\title{
Student loans in Japan: Current problems and possible solutions
}

\author{
Shiro Armstrong ${ }^{\mathrm{a}}$, Lorraine Dearden ${ }^{\mathrm{b}, *}$, Masayuki Kobayashi ${ }^{\mathrm{c}}$, Nobuko Nagase ${ }^{\mathrm{d}}$ \\ a Australia-Japan Research Centre, The Australian National University, Australia \\ ${ }^{\mathrm{b}}$ University College London, Institute for Fiscal Studies and IZA, United Kingdom \\ ${ }^{\mathrm{c}}$ Center for Research and Development for Higher Education, The University of Tokyo, Japan \\ d Ochanomizu University, Japan
}

\section{A R T I C L E I N F O}

\section{Keywords:}

Student loans

Student loan design

Japan

JEL Codes:

$\mathrm{H} 28$

H28
I22

I28

J24

\begin{abstract}
A B S T R A C T
The Japanese higher education sector has seen increases in tuition with stagnant household incomes in a society where family support for university students has been the norm. Student loans from the government have grown rapidly to sustain the gradual increase in university enrolments. These time-based repayment loans (TBRLs) have created financial hardship for increasing numbers of loan recipients and their families. There is some evidence that prospective students from low-income households are forgoing a university education to avoid student loan debt. The Japanese government has introduced some measures including grants and a partial income-contingent loan (ICL) scheme to help alleviate these problems.

While the ICL scheme is a positive development, this paper shows that it requires further refinement and broader coverage if it is to adequately address the challenges facing higher education financing in Japan. We show that an affordable and universal ICL system could be introduced in Japan that avoids problems with the current partial income-contingent loan scheme and would help alleviate access issues for those from disadvantaged backgrounds. Importantly, the unique features of the Japanese labor market have to be carefully considered, especially the large gender wage gap for married women. By introducing dynamics into modeling graduate earnings and using carefully selected parameters, we show that it is possible to have a universal ICL which achieves a balance between access and affordable repayment with minimal long-run costs to taxpayers.
\end{abstract}

\section{Introduction}

Japan's higher education sector is facing financing and access challenges. The country's aging population and low birth rates mean that student cohort sizes are falling over time, while the number of private universities continues to increase. The government's fiscal position, running primary deficits with a gross debt-to-GDP ratio of $245 \%$ in 2018, makes subsidizing the sector increasingly difficult. Furthermore, stagnant wages and household incomes, coupled with gradually rising tuition fees, are making access to university a bigger issue for society.

There are many challenges facing universities in Japan, such as their drive to internationalize and maintaining international competitiveness. For many private universities, financial viability is a growing challenge and there are questions over quality in some private universities. Any reform or expansion of the student loan system would need to involve provisions to ensure that loans are only available to high-quality universities for suitably qualified students. This is already an issue with the current funding system.

At the same time, there is evidence that the labor market for Japanese graduates is changing as described in Section 3 below. Increasingly, more university graduates are entering non-standard employment with less job-security, so understanding the dynamics of the graduate labor market is crucial to designing a sustainable loan system. Traditionally, Japanese university students have relied on parents to fund their university education, but prolonged tight economic conditions have impacted the ability of parents to pay, and in recent years the number of students taking out student loans has increased rapidly. The rising numbers of graduates accessing non-standard employment, and the longstanding issue of low wages for female graduates in the bottom half of the earnings distribution, have meant that an increasing number of graduates (and their families) are facing student loan repayment hardship. There is also qualitative evidence suggesting that the cost of funding the education of children is impacting on fertility decisions. ${ }^{1}$

\footnotetext{
* Corresponding author.

E-mail address: 1.dearden@ucl.ac.uk (L. Dearden).

${ }^{1}$ According to the $15^{\text {th }}$ Japanese Fertility Survey of $2015,56.3 \%$ of couples replied that the cost of child-rearing and education was the reason for not being able to have their ideal number of children. This reason was the highest of the 12 options given.
} 


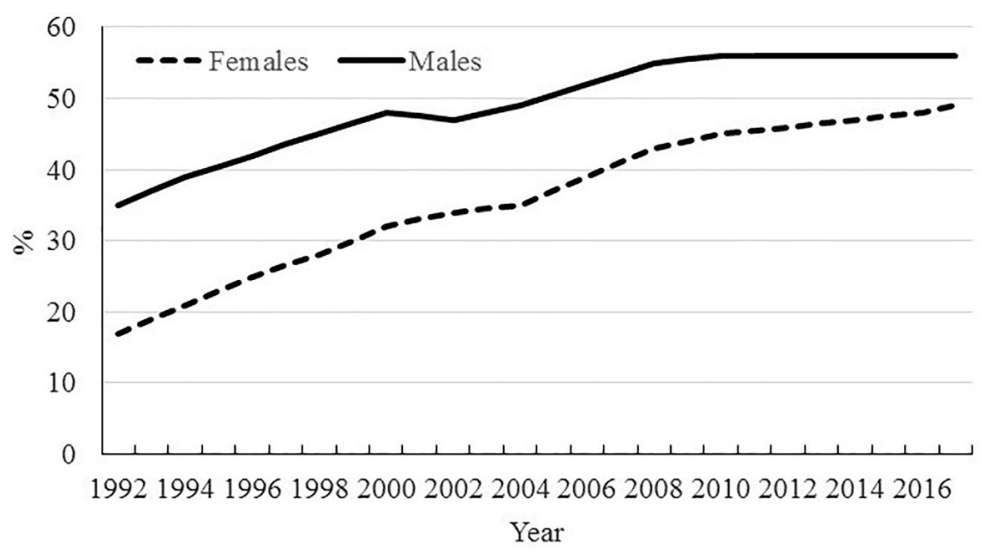

Fig. 1. Proportion of four-year BA degree enrolment by gender.

Source: MEXT, 2016b.

In this paper, we highlight the problems with the current Japanese higher education loan system, including the recently introduced smallscale, partial-coverage, income-contingent loan (ICL) scheme. With an ICL, graduates and other university leavers repay student loan debts through employer with-holding once their incomes have reached a certain threshold, with no repayment until that threshold is reached. We use Japanese microdata to look in detail at the current problems with the Japanese student-loan system and outline possible approaches to solving these problems using a universally available ICL.

Our analysis shows that Japan is different from other countries that have introduced ICLs and that simply adopting an ICL scheme from any of those countries is unlikely to work effectively. This is mainly because, historically, female Japanese graduates have comparatively low earnings compared to male graduates once they get married or have children. ${ }^{2}$ This is very different from countries like Australia and the UK, where the gender differences in the wages of graduates are much less marked, even after marriage or having a child. ${ }^{3}$ While recent evidence Nagase (2018a) suggests that this is changing for younger cohorts, Japanese cultural and economic factors mean it is likely to be a feature of the graduate labor market for the foreseeable future. Hence, a sustainable ICL system would need to take this into account.

In Section 2, we provide a background to university funding and student loans in Japan. In Section 3, we look at recent trends in the Japanese graduate labor market and use data from the Japanese Labor Force Survey (LFS) combined with panel data from the Japan Household Panel Survey (JHPS/KHPS) ${ }^{4}$ to simulate dynamic graduate earnings by gender. In Section 4, we show the typical repayment burdens associated with the current Japanese mortgage-style loan system, which helps explain why default rates have been increasing in Japan. In Section 5, we show why the current Japanese ICL scheme introduced in 2017 does not solve this problem for lowearning graduates and how a universal, affordable and sustainable ICL loan scheme could be introduced in Japan. Our work suggests that this would involve having parameters that are different to the ICL schemes operating in Australia and England but, we argue, would be significantly better than the current mixture of TBRL and

\footnotetext{
${ }^{2}$ In this paper, we use wages in an hourly context, and earnings to account for annual income from work excluding non-salary components.

${ }^{3}$ Japan had the third largest gender wage gap in the OECD in 2017, significantly higher than that of Australia or the United Kingdom, source: http:// www.oecd.org/gender/data/gender-wage-gap.htm

${ }^{4}$ We use the combined Japan Household Panel (JHPS/KHPS) survey, which merges data from the "Keio Household Panel Survey" (KHPS) from 2004 with data from the "Japan Household Panel Survey" (JHPS), which started in 2009. See https://www.pdrc.keio.ac.jp/en/paneldata/datasets/jhpskhps/ for more information about the panel data.
}

partial ICL loan arrangements. Section 6 provides a conclusion to the paper.

\section{Policy background}

\subsection{University enrolment and participation}

As of 2015, there were 86 national universities, 89 public (or municipal) universities and 604 private universities and colleges competing for students in Japan (MEXT, 2016a). ${ }^{5}$ University enrolments have been rising at an average rate of $1.4 \%$ per year over the last three decades. This peaked at about 2.9 million students in 2011 and stood at 2.6 million in 2016 (MEXT, 2016a).

There are also other forms of tertiary education in Japan. The number of students in specialized training colleges (senmongakko) has increased considerably over the last four decades, from about 10,000 in 1977 to about 657,000 in 2016 whereas the number of students in technical colleges (kotosenmongakko) has been stable since the mid1980 s at around 60,000 students. Students in junior colleges peaked in 1995 at about 500,000, then fell to around 130,000 in $2016 .{ }^{6}$ More students from lower income backgrounds attend specialized training colleges than technical colleges or junior colleges. In this paper, we focus on funding and loans for university students, but student loans are also available to these other forms of tertiary education.

The percentage of high school graduates entering four-year university (what we will term BA graduates in this paper) has been rising steadily for both males and females since the early 1990s, as illustrated in Fig. 1. In the past, females typically went to two-year junior college for a post-secondary education. However, the demand declined when the labor market for two-year college graduates stagnated and as the internal rate of return for four-year university programs surpassed that of two-year junior colleges for women. Today, the proportion of women undertaking four-year BA degrees is at a historical high at just under $50 \%$.

Fig. 1 also illustrates the narrowing of the gender gap in university enrolment since the early 1990 s. In $2016,44.1 \%$ of university students were women-more than double the number than in $1992 .^{7}$ This increase has no doubt been due to the growing demand for higher education, as well as to the increase in the provision of four-year university facilities and the expansion of loans available to university students through the Japan Student Services Organization (JASSO). JASSO is a quasi-governmental agency and is the largest provider of student loans in Japan.

\footnotetext{
${ }^{5}$ Ministry of Education, Culture, Sports, Science and Technology (MEXT).

${ }^{6}$ See MEXT (2016b).

${ }^{7}$ See MEXT (2016a).
} 


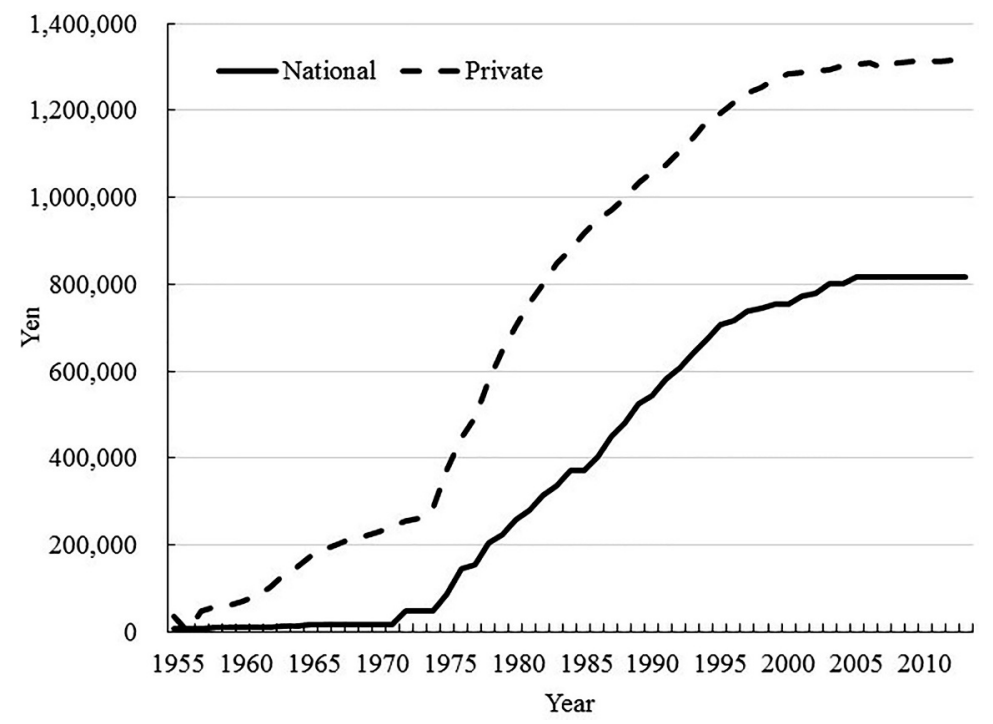

Fig. 2. Tuition fees 1955-2014.

Source: MEXT, Changes in Tuition Fees of National Universities and Private Universities (http://www.mext.go.jp/b_menu/shingi/kokuritu/005/gijiroku/attach/ 1386502.htm).



Fig. 3. The ratio of tuition fees to family disposable income.

Note: the ratio is tuition fees for one year to monthly family disposable income.

Source: MEXT (see Fig. 2 source note) and Statistical Bureau "Household Survey".

\subsection{University tuition fees}

University tuition fees for both national and private universities rose dramatically between the late 1970 s and early 2000s. Since then, national university tuition fees have plateaued, and those for private universities have grown much more slowly (Fig. 2). The slowdown in the growth of tuition coincides with the stagnation of wage growth and the onset of deflation in the late 1990s following the slowdown of the Japanese economy after the asset bubble burst at the beginning of that decade. The tuition fees charged by national universities in 2016 were more than 40 times higher than in 1972 in current prices. ${ }^{8}$ The increase in expenditure and limited capacity for government subsidization has led most universities and colleges to raise their fees.

Government subsidies to national universities have been falling by $1 \%$ per year since 2004 . Government spending was about 12.4 billion yen in 2004 and declined to about 10.9 billion yen in 2016. Given the Japanese government's fiscal position, there is little capacity for further

\footnotetext{
${ }^{8}$ All values are reported in current prices unless otherwise specified. The CPI was at or slightly below zero from the late 1990s until the mid-2010s.
}

funding, and the trend of reduced subsidies is likely to continue. Government subsidies to private universities and colleges were stable over that 12-year period, although the ratio of subsidies to current expenditure decreased to less than $10 \%$. Almost three out of four students attend private universities in Japan.

Although the increase in tuition fees has been modest in recent years, family disposable income has been decreasing. This has led to a gradual increase in the ratio of tuition fees to family disposable income (Fig. 3). In Japan and other East Asian countries, parents have traditionally been responsible for financing the education of their children. Thus the burden of tuition on families has been increasing, especially for low-income families.

The household share of higher education expenditure is more than half of the total expenditure on higher education in Japan, and among the most expensive in the world (see OECD, 2015). Public expenditure on tertiary education is among the lowest for OECD countries. Households in Japan already bear a significant burden of higher education costs, but the cost-sharing trend in Japan, as elsewhere, is moving away from public toward private sources.

While tuition fees of Japanese universities and colleges have become less affordable, the availability of public grants and scholarships 


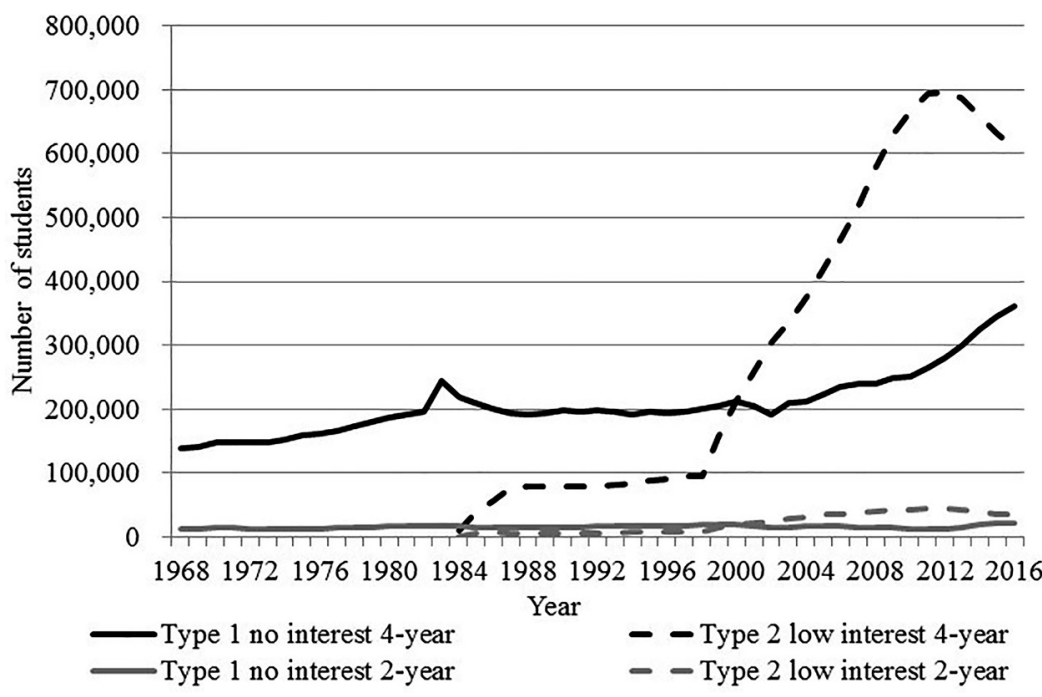

Fig. 4. Changes in student numbers receiving JASSO loans.

Source: Nihon Ikueikai (Japan Student Scholarship Foundation) and JASSO Annual Reports, various years.

for undergraduate students both in the public sector and the private sector has decreased. The exception is with university tuition waivers which are equivalent to student grants. The budget for tuition waivers for students increased from 21.5 billion yen in 2004 to 43.4 billion yen in 2017 (MEXT, 2017). Each university has discretionary power to decide how to allocate tuition waivers.

\subsection{Student loans}

The growth in university enrolments has been sustained by an increase in student loans provided by the government and, in particular, student loans from JASSO. JASSO provides two types of time-based repayment loans (TBRLs), which require repayment at fixed time intervals. Of the two types of loans, the growth of Type 1 (interest-free) loans has been modest (Fig. 4), while the growth of Type 2 (low-interest) loans, introduced in 1984, has been increasing rapidly, both for four-year and two-year undergraduate students. The dramatic growth of Type 2 loans is due to the substantial relaxation of eligibility criteria in 1999.

Type 1 loans are awarded based on both merit and need. They are interest-free and not indexed to inflation. Type 2 loans are interest-free during university years, with a maximum interest rate of $3 \%$ after graduation, and are awarded based on economic need, though the eligibility criteria are widening to include those from middle-income families. The interest rate charged on Type 2 loans is negligible at $0.33 \%$ for the fixed interest rate option and $0.01 \%$ for the variable interest rate that is altered every 5 years (as of May 2017-see JASSO, 2017). Neither loan type is associated with fees.

The total budget for both types of loans was 1.08 trillion yen in the fiscal year 2017, having fallen from a peak of 1.2 trillion yen in the fiscal year 2013. ${ }^{9}$

The size of each loan varies according to the type of loan, whether the student is attending a private or national/public university, and whether they live at or away from home. Loan amounts for Type 1 loans vary from 45,000 yen per month for four-year university students living at home attending a national or public university, to 64,000 yen per month for four-year university students attending a private university away from home. The time-based repayments require monthly instalments for periods of 13-20 years depending on the loan amount (see JASSO, 2017).

\footnotetext{
${ }^{9}$ JASSO (2017), p. 6
}

Students apply for the loans and are selected through the school from which they graduate prior to university or through the Higher Education Institutes (HEIs) they attend. Students taking on a JASSO loan must have a parent and other relative agree to act as a guarantor on the loan, or have the Japan Educational Exchanges and Services (JEES) act as an institutional guarantor. Overdue repayments are charged interest at the rate of $5 \%$ per year. This rate is significantly lower than the $10 \%$ per year charged until the end of March 2014. If the loan recipient is unable to repay the loan, legal action is taken against the guarantor. In the case of the institutional guarantor, JEES is likely to take legal action against the loan recipient if they are unable to repay. There are provisions for deferment and reduced repayments if facing hardship, but individuals have to apply for this annually. $30 \%$ of Type 1 students who undertake graduate degrees can have their loans partially or wholly exempted if they have an "outstanding" academic record. Both Type 1 and Type 2 borrowers account for just under $40 \%$ of all university students and around $45 \%$ of all students. The rate of collection, as reported by the administering agency JASSO, was $96.7 \%$ in the fiscal year $2015 .{ }^{10}$

When modeling student loan design, it is important to know the distribution of loan amounts and who takes out loans. The distribution of loans for four-year university students excluding night students from a 2014 JASSO sample survey (with population weights) is shown in Table 1 . We use the more disaggregated version of this data in our simulations below. The average monthly loan was 75,724 yen.

\subsection{Recent reforms to Type 1 loans}

A new ICL scheme was adopted in April 2017 for Type 1 JASSO loan borrowers. Type 1 JASSO loans covered around $37 \%$ of borrowers and $14 \%$ of university students in 2016 (Fig. 4). The ICL option is not available for those borrowers taking out the more common Type 2 lowinterest student loans as of 2017. Repayment rates are contingent on income under the new scheme. The repayment rate is $9 \%$ of the borrower's taxable income. A borrower can choose between a TBRL with fixed monthly repayments or the new ICL plan before graduation. ${ }^{11}$ Taxable income in Japan is gross income minus income deductions for earned income deduction, social security contributions (pension and health insurance), basic personal deduction and spouse deduction (contingent on both the primary earner's and spouse's gross earnings).

\footnotetext{
${ }^{10}$ See JASSO (2017), p. 7.

${ }^{11}$ Borrowers can change from TBRL to ICL after graduation once, but not the other way around.
} 
Table 1

Distribution of JASSO loans in 2014.

\begin{tabular}{llll}
\hline $\begin{array}{l}\text { JASSO monthly loan } \\
\text { in yen }\end{array}$ & $\begin{array}{l}\text { Number of } \\
\text { students }\end{array}$ & $\begin{array}{l}\text { Distribution } \\
\text { among all } \\
\text { borrowers (\%) }\end{array}$ & $\begin{array}{l}\text { Distribution } \\
\text { among all students } \\
(\%)\end{array}$ \\
\hline $5-30,000$ & 98,977 & 9 & 4 \\
$30,001-40,000$ & 101,886 & 10 & 4 \\
$40,001-50,000$ & 24,963 & 2 & 1 \\
$50,001-60,000$ & 272,996 & 26 & 11 \\
$60,001-70,000$ & 129,764 & 12 & 5 \\
$70,001-80,000$ & 67,495 & 6 & 3 \\
$80,001-100,000$ & 148,731 & 14 & 6 \\
$100,001-125,000$ & 105,031 & 10 & 4 \\
$125,001-150,000$ & 71,403 & 7 & 3 \\
$150,001-270,000$ & 46,713 & 4 & 2 \\
No loan & $1,318,644$ & & 55 \\
All students & $\mathbf{2 , 3 8 6 , 6 0 0}$ & & $\mathbf{1 0 0}$ \\
\hline
\end{tabular}

Source: JASSO Students' Survey (2014) - calculated from microdata of JASSO "Student Survey 2014" for four-year university students, excluding night students.

The scheme involves a minimum repayment of 2,000 yen per month for borrowers with gross annual incomes of between zero and 1.44 million yen a year (equivalent to a taxable income of between 0 and 0.27 million yen). ${ }^{12}$ The 2,000 yen per month minimum repayment is an attempt to balance the interest of recovering ICL debts in an environment with high government debt and fiscal pressure. If a low earning graduate has a high earning partner then they are put back on the TBRL rather than the ICL. As is the case in Australia, the debt is written off only if the borrower becomes disabled, permanently ill, or in the event of death.

\section{The graduate labor market and graduate earnings in Japan}

\subsection{The Japanese graduate labor market}

Up until the late 1980s, the graduate labor market in Japan was quite stable and most graduates found long-term employment after graduation. After the asset bubble burst in 1991, the conditions in the graduate labor market worsened as the economy stagnated. The Japanese economy has experienced slow growth since then, with growth averaging below $1 \%$. One feature of the Japanese labor market is the "lifetime employment" system (seishain) where once a graduate gets a full-time job in a company or civil service at graduation, he or she is entitled to work there until the mandatory retirement age. The system also includes seniority-based wages where earnings increase with tenure. The seishain system guarantees stable employment and was a positive feature of the labor market during periods of rapid economic growth because firms could invest heavily in the human capital of employees without fear of losing them to competing firms. With a stagnant economy, some argue that the system is now a drag on the economy given that it inhibits labor mobility (Yashiro, 2011).

Labor market flexibility has been introduced with an increase in the share of non-regular employment (non-seishain) that does not feature long contracts, significant job security or seniority pay. This has led to a bifurcation of the labor market (Miyamoto, 2016) with roughly 40\% now nonregular workers. This has meant that graduates who do not find stable or full-time employment may have difficulty with loan repayments between jobs.

Data from the Japanese Labor Force Survey (LFS) show that males on average have a higher probability of getting regular full-time employment, seishain, once they have graduated from university or school.

\footnotetext{
${ }^{12}$ See JASSO (2017) and Fig. 11 below. Annual revenue is what we refer to as gross earnings. Total income is what we refer to as taxable income. The JASSO ICL is $9 \%$ of taxable (total) income.
}

For males, the ratio of seishain is around 50\% for high school graduates one year after graduation, while for university graduates in 2002 it was $69 \%$ and for graduates in 2009 it was $74 \%$. This proportion continues to rise every year after graduation, with around $90 \%$ of male university graduates in seishain 10 years after graduation (Nagase, 2017).

While female university graduates have a higher percentage of seishain (70\%) compared to female high school graduates $(40 \%)$, the percentage of seishain for both groups declines steadily every year after graduation. While there has been an increase of around 5-7 percentage points in the proportion of seishain by age between the 2002 and 2009 cohorts of female university graduates, only $45 \%$ remain in seishain 12 years after graduating. This reduction is generally associated with marriage and/or having a child where more women leave the labor force or change their jobs to non-standard employment. Mothers often re-enter the labor market, but mostly as non-standard hourly employees, instead of as seishain. There has been some increase in university-graduated mothers continuing to work as a seishain after the short hour option was mandated in 2010, and also as a result of the combination of Womanomics policies after 2013 (Nagase, 2018a).

Seishain, or standard employment, is associated with higher incomes than non-standard employment and the share of women in seishain work falling with age is causing a persistent and widening gender wage gap.

\subsection{The distribution and dynamics of graduate earnings in Japan}

For analyzing and designing student loan systems, it is important to see what implications these labor market features have for the distribution of graduate earnings by age, as well as earning dynamics for Japanese graduates. To look at this, we use two Japanese data sources. The first is the Japanese LFS data, which is the best source of crosssectional earnings data in Japan. Our LFS sample is taken from the monthly data of the 2015, 2016, and 2017 surveys. Our second source of data is the combined Japanese Household Panel Survey (JHPS/ KHPS) which covers the period from 2004 until 2016.

The LFS is a nationally representative survey conducted every month that covers about 40,000 households and about 100,000 individuals over the age of 15 . It is a rotating panel and households are surveyed four times in the same adjacent two months in two successive years. From January 2002, the survey began to collect data on the fourth and last visit to households using a longer questionnaire, which asked not only about labor force status, but also about educational attainment, tenure and annual income in the previous year for all relevant individuals in the household. Data from this longer questionnaire are used in this analysis. We limit our sample to those who graduated from university or postgraduate study, aged between $23^{13}$ and 65 , and who undertook their fourth LFS interview between January 2015 and May 2017, giving a sample of 53,459 males and 29,137 females.

Our JHPS/KHPS panel consists of 4,950 university graduates followed for between 1 and 13 years, with the average time in the panel being 8.13 years. $64.4 \%$ of the panel are males and $35.6 \%$ females. For those aged 23 in our panel, $57.1 \%$ are males and $42.9 \%$ females, reflecting the increase in university participation by women illustrated in Fig. 1. This means we have 28,496 graduate earnings observations: 18,309 for males and 10,187 for females.

In designing student loan systems and understanding the repayment burdens associated with student loans, it is important not only to know average graduate earnings, but graduate earnings across the entire earnings distribution. One problem with the LFS earnings data is that it is banded into income groups rather than recording the actual level which makes estimating income profiles across the earnings distribution more complicated. Following Dearden (2018), we get around this

\footnotetext{
${ }^{13}$ In our LFS sample we merge any 22-year-old BA graduates with the 23year-old graduates, as the number of 22-year olds is relatively small.
} 
by using interval regression and the rich covariates contained in the LFS to estimate continuous earnings measures within each income band. ${ }^{14}$ This is not necessary for the JHPS/KHPS panel data where earnings are not banded.

We then calculate the percentiles of the earnings distribution (including zeros) in both data sets and smooth these profiles using flexible polynomials in age following Dearden (2018). The estimated ageearnings profiles for BA male graduates using both the LFS data and JHPS/KHPS panel data are shown in Fig. 5 and the corresponding estimates for females are shown in Fig. 6.

From Fig. 5 we see that for males, the estimated quantile earnings profiles are reassuringly similar when we use the JHPS/KHPS panel data and LFS data. The only marked differences are for men with relatively high earnings (the 75th percentile and 90th percentile of the BA earnings distribution). The LFS shows lower earnings at the 75th percentile and higher earnings at the 90th percentile from the age of 40 onwards. This simply could reflect the fact that the data is taken from different years (the LFS is a more contemporaneous cohort whereas the JHPS/KHPS covers the years 2004-2016) or the censoring of the LFS at high earnings. There is also an issue of higher attrition in the panel for those in the lowest and highest income groups. ${ }^{15}$ Dearden (2018) showed that the interval regression method used for turning banded earnings into a continuous measure is not as reliable for high earnings, and this may explain some of the observed differences.

In our analysis, we use percentile estimates from the LFS sample as it is more recent and involves larger sample sizes. The data suggest that median-earning, four-year university-educated males are earning around 5 million yen by the age of 35 . This rises to about 7.5 million by the age of 55. Males in the bottom 10th percentile never earn above 1.5 million yen per year. Those in the 20th percentile of the earnings distribution earn about half of the median earnings whereas those in the 90th percentile earn between $50-75 \%$ more than median earnings throughout most of their working life. The variance in graduate earnings increases up until about the age of 55 before narrowing in the runup to retirement. This is typical of most male earning profiles seen in other countries and featured in this special issue of the EER.

In Fig. 6, we see the corresponding estimates for females. This shows a very different picture compared to males and compared to females in other countries. Typical age-earnings profiles are only seen for women in the top quarter of the earnings distribution. Median-earning women never earn above 3 million yen per annum, and at most ages earn well below this figure. It appears that the situation is improving slightly for the younger cohort covered in the LFS data, ${ }^{16}$ but the increase in earnings is modest in all parts of the earnings distribution. There are, however, significant differences in the earning profiles from the two data sets, particularly at older ages. This may be due to cohort effects.

\footnotetext{
${ }^{14}$ The LFS data has 10 income bands. Our explanatory variables include: tenure, hours of work, age, firms size dummy variables, marital status, dummy variables for ages of children in households, number of children in the household, dummy variables identifying the type of employment, as well as detailed industry and occupation dummy variables. Full details are available from the authors.

${ }^{15}$ Male earnings in Japan have been declining since 1997, with some upturn following the so-called 'Abenomics' policies (the economic reforms of Prime Minister Shinzo Abe) since 2013. The difference may reflect some real differences in earnings because of the different time periods covered; it could also reflect differences in response rates in the two surveys. Response rates in the LFS are significantly higher than those in the JHPS/KHPS, and panel attrition will make this problem worse as the panel ages (Naoi \& Yamamoto, 2010). This almost certainly means that coverage of low earners will be better and more representative in the LFS. Differences at high earnings are not particularly crucial for loan design unless there is very high earnings mobility. This is not the case in Japan.

${ }^{16}$ Nagase (2018a) shows that the proportion of female university graduates continuing their seishain job after the birth of their first child has increased since 2010, and it further increased after 2013.
}

Dearden and Nagase (2017) compared the same LFS data with data from the cross-sectional Japanese General Social Surveys (JGSS) between 2000 and 2012. Both data sources gave very similar profiles at younger ages, with small differences emerging at older ages likely due to cohort effects (lower earnings in the JGSS data at older ages). This suggests the observed differences between our panel data and LFS is probably due in part to cohort effects, but also to panel attrition, nonresponse issues and/or relatively small sample sizes. ${ }^{17}$

What lies behind the low female earnings? What is clear from the LFS data is that it is not low labor force participation. It is instead low earnings for graduate women in work. Interestingly, at young ages, women in the bottom half of the graduate earnings distribution earn more than males in the bottom half of the earnings distribution. This is because young male graduates remain unemployed in order to obtain seishain while female graduates are more likely to opt for some earnings in non-seishain (Nagase, 2011).

Nagase (2018b) argues that there are further institutional reasons why a significant proportion of female BA graduates earn very little. She shows that a significant portion of women quit full-time work, or any paid work, once they have a child, and firm hiring policies often penalize workers who leave the labor market and re-enter during middle age (predominantly mothers returning to work). A large proportion of firms pay a spouse allowance for long-term employees who have dependent housewives, and this allowance is often taken away when their spouse's earnings exceed the first tax threshold or social security tax exemption, though the policy differs according to firms.

This practice is changing, but still has obvious disincentives for women working. In addition, the Japanese social security system has generous protection for the spouses of wage earners. They are exempted from social security tax and given rather generous coverage for basic pension, as well as full coverage of health and old age insurance, so long as their earnings are below 1.3 million yen a year. From September 2016, part-time workers earning more than 1.06 million yen a year and working 20 hours or more a week at firms with over 500 workers are levied social security tax. These tax and social security regimes coupled with spousal allowance and deductions mean many married women earn just below these tax and social security thresholds. ${ }^{18}$ This bunching is very clear in the Ministry of Health, Labor and Welfare's Longitudinal Survey of Adults in the 21st Century data as shown by Nagase (2018b). There is currently a lot of policy debate in this area in Japan, promoted in part by significant demographic changes which have seen a rapid decline in the working age population; this is the context in which the student loans system needs to work.

If we instead focus on the earnings of single BA graduates, the gender differences are much less stark as shown in Fig. 7. It shows that when we limit the sample to non-married males and females, the BA gender wage gap narrows substantially, and is similar to the gender gaps seen in other countries. At the bottom of the income distribution, there is very little difference between men and women, and median earnings only significantly differ from the age of 40 . This again could be a cohort rather than an age effect. Of single BA graduates, it is only those in the bottom of the earnings distribution that will face potential hardship from repaying student loans. This is explored further in Section 4.

\subsection{Introducing earning dynamics}

We follow the method of Dearden (2018) and use our age-earnings profiles by percentile from the LFS survey to approximate the marginal

\footnotetext{
${ }^{17}$ See Naoi and Yamamoto (2010) for more details.

${ }^{18}$ From 1.03 million yen a year, tax is levied for wage earners. From 1.3 million yen a year, a spouse would need to pay their own social security tax. The threshold for claiming spousal deduction has been raised from 1.03 million to 1.5 million per year from 2018. All these changes are included in our simulations below.
} 

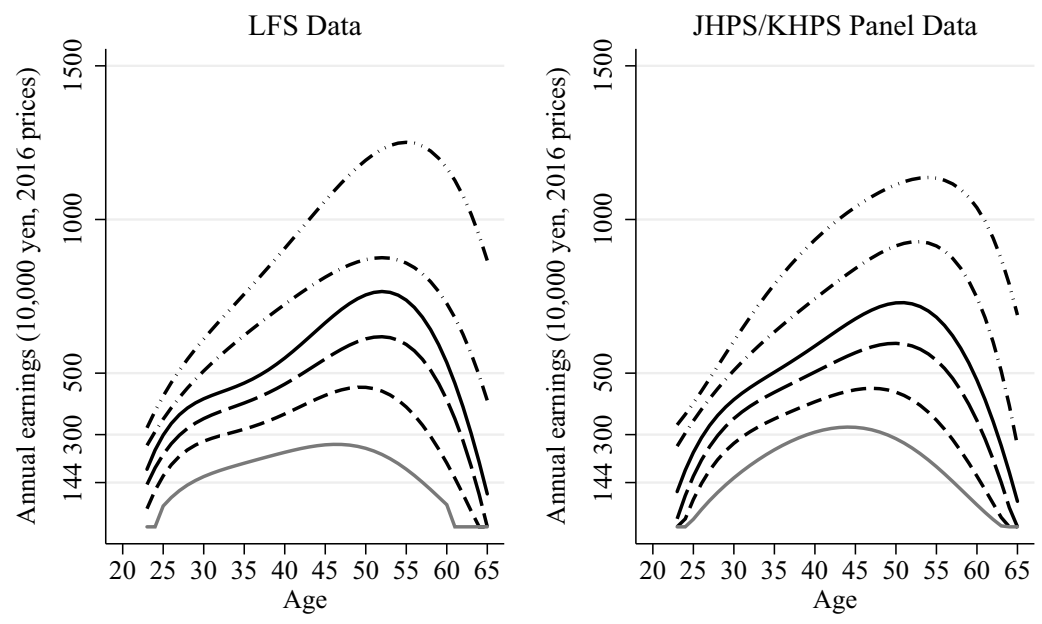

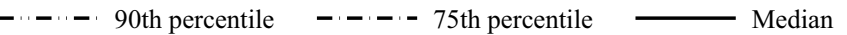

$$
\begin{aligned}
& \text { - - }-35 \text { th percentile } \quad-----20 \text { th percentile _ } \quad \text { 10th percentile }
\end{aligned}
$$

Fig. 5. Quantile estimates of male BA graduate earnings: LFS and JHPS/KHPS data.
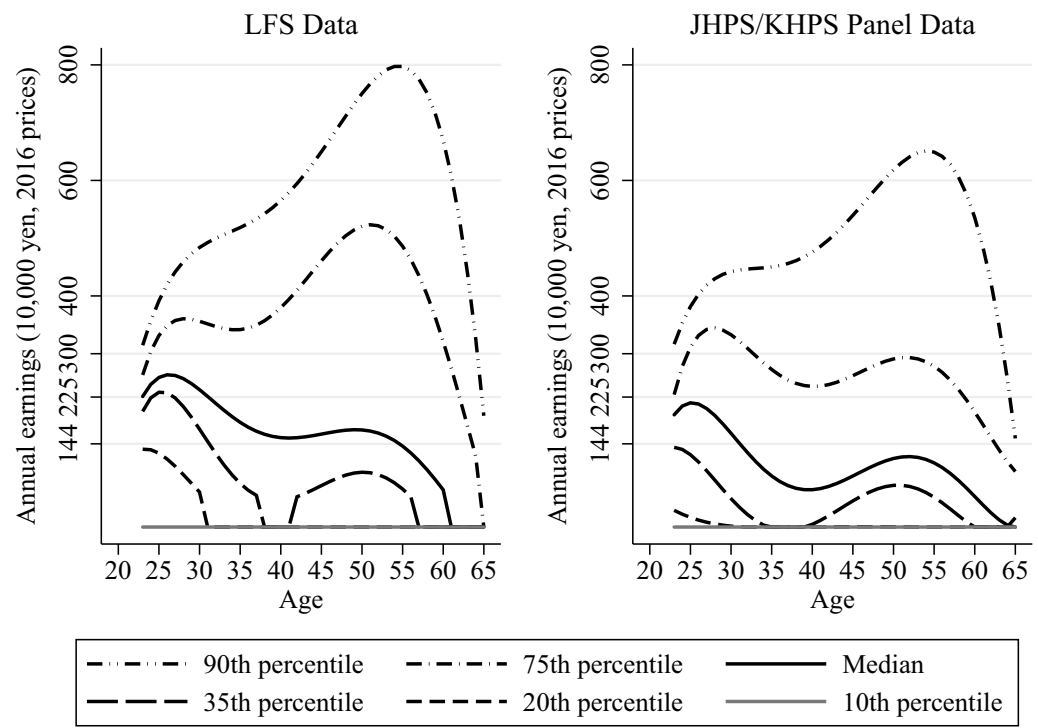

Fig. 6. Quantile estimates of female BA graduate earnings: LFS and JGSS/KHPS data.

distribution of graduate earnings at each age from 23 to 65, which we will use in our simulations.

We then use copula models to estimate the joint distribution of the adjoining continuous marginal cumulative distribution function (CDF) of earnings at each age in our JHPS/KHPS panel data. ${ }^{19}$ From Sklar (1959) we know there exists a copula function that exactly defines this joint bivariate distribution. In Japan, we have up to 13 earnings observations per individual, but we find that a bivariate copula, which assumes first-order Markov dependence, matches the dependence observed in the panel data well. Our estimation approach involves finding the bivariate copula that best captures the joint distribution of the adjacent marginal earnings distributions, essentially the continuous transition matrix for earning rank transition from the age of 23 to 64 and hence similar to the transition matrix approach of Higgins and Sinning (2013).

As was the case for the US (see Dearden, 2018), Brazil (Dearden \&

\footnotetext{
${ }^{19}$ The marginal CDFs are uniformly distributed between 0 and 1 and hence can be easily mapped onto the percentile estimates of the marginal distributions at each age once the simulations have been completed.
}

Nascimento, 2018) and England (see Dearden, Fitzsimons, Goodman, \& Kaplan, 2008), the t-copula provided the best fit for most age transitions for both male and female graduates in the JHPS/KHSP panel. As explained in Dearden (2018), the t-copula has two parameters: the correlation parameter $\rho$ (rho) and the degrees of freedom parameter $\nu$ (df). The $\rho$ parameter describes the overall level of immobility in earning transitions, with a higher $\rho$ meaning less earnings mobility between adjacent ages. The $\nu$ parameter measures the extent of taildependence in the transition. The lower the $\nu$ parameter, the lower the mobility in the tails of the earnings distribution. Figure 8 shows the results of our estimation procedure (and confidence interval for the estimates), as well as non-parametrically, smoothed estimates of rho, which we use in our simulations. ${ }^{20}$

The estimates of rho in Fig. 8 show an increasing level of immobility in the earnings distribution for graduates in Japan until late their $50 \mathrm{~s}$ for both men and women, with slightly more immobility for women.

\footnotetext{
${ }^{20}$ We smooth estimates up to the age of 59 . It is clear that in our data, many graduates retire at the age of 60 . For these transitions, we use our raw (unsmoothed) estimates.
} 

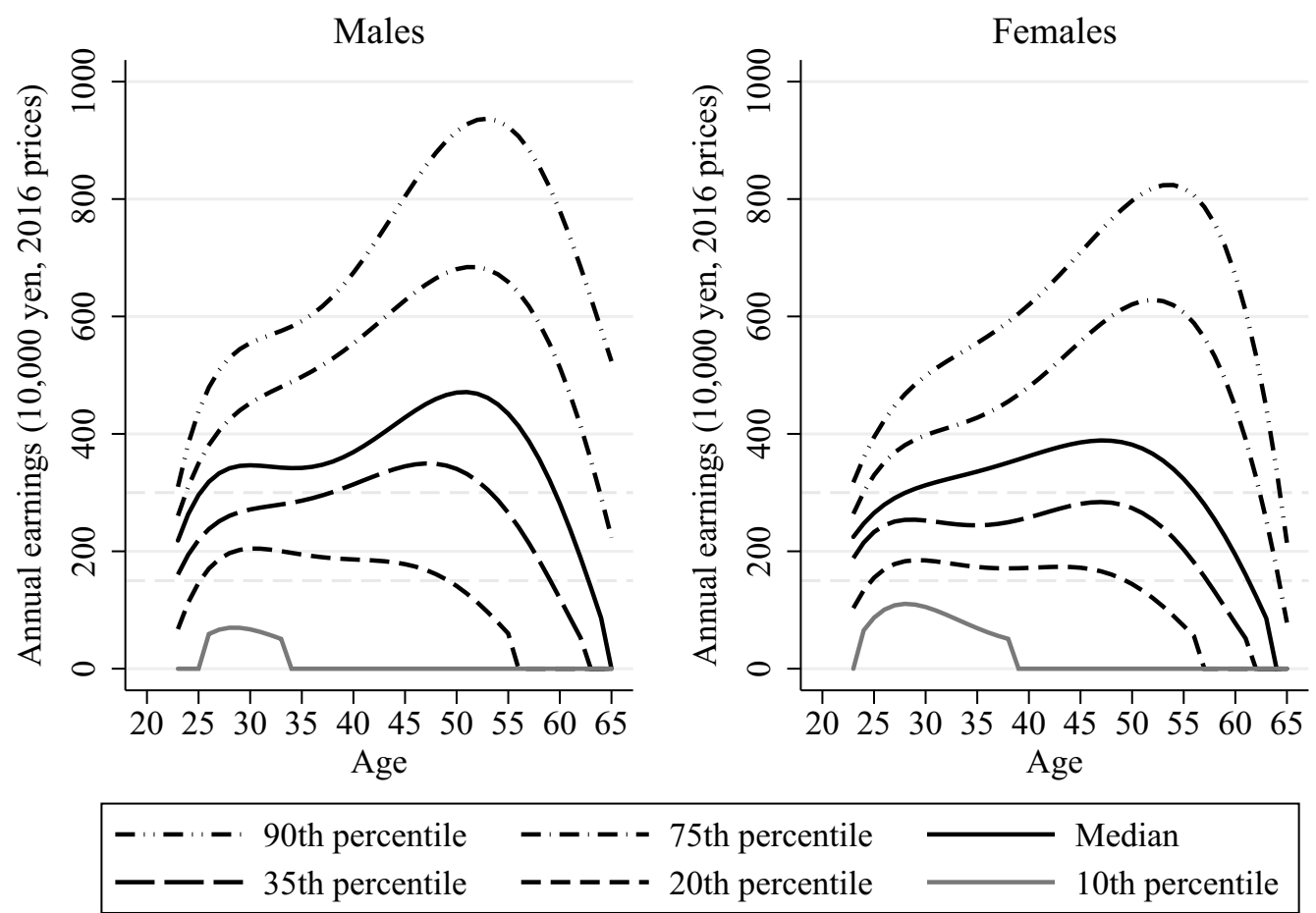

Fig. 7. Quantile estimates of single BA graduate earnings: LFS data.
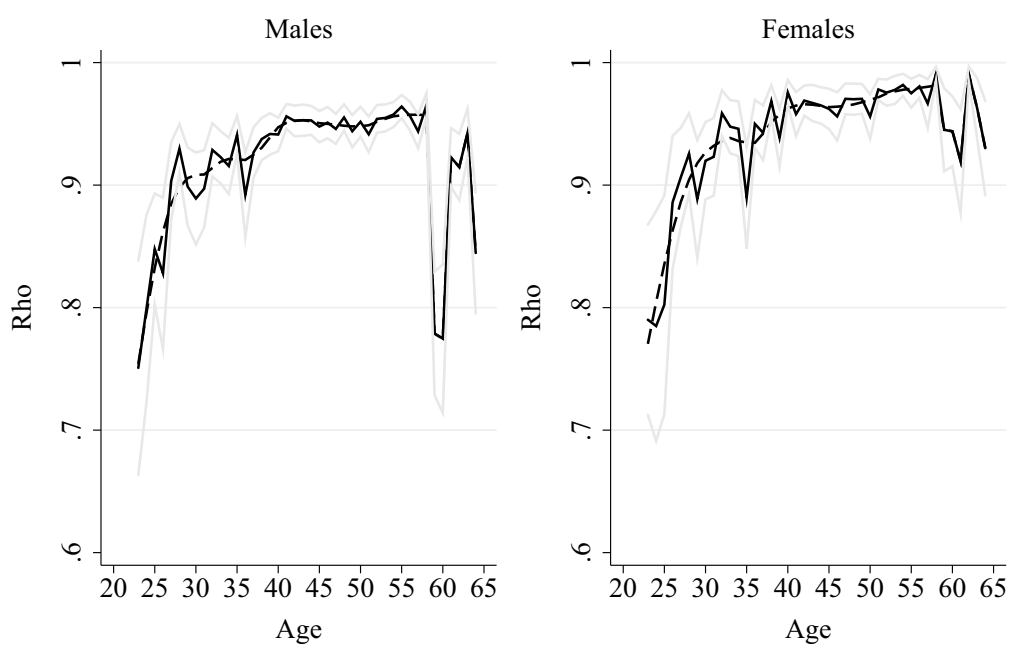

Estimated rho

$\mathrm{CI}$

- - - - Rho used in simulations

Fig. 8. Estimates of rho $(\rho)$ from t-copula.

Earnings become significantly more mobile for males after that time (particularly around the age of 60) and slightly more mobile for females (with less of a decline at 60). Fig. 8 implies considerably less earnings mobility among graduates in Japan compared to US graduates examined by Dearden (2018) and Brazilian graduates examined in Dearden and Nascimento (2018).

The other parameter, $\nu$ (the degrees of freedom), measures tail-dependence; that is, excess immobility in the tails of the distribution. The lower the $\nu$ parameter, the lower the mobility in the tails. Fig. 9 shows by age the degrees of freedom estimates (df or $v$ ), the confidence intervals, and the corresponding non-parametrically smoothed estimates of $v$ for both males and females.

Fig. 9 shows that individuals at the bottom (or top) of the earnings distribution face higher chances of upward (or downward) mobility in the first years after graduation but not after. However, because there are large confidence intervals at early ages some caution is needed with this conclusion. We also repeat this exercise and estimate household earning dynamics for BA graduates, which allows us to simulate the earnings of the partners of BA spouses (crucial in calculating taxable income, which is the basis of the current JASSO ICL loan). This is discussed in Section 5.

Having obtained our t-copula estimates, we have a relatively straightforward way of simulating forward for a sample of 23-year-old graduates. We assume that $45 \%$ of graduates are female and $55 \%$ are males. ${ }^{21}$ Our simulation approach involves:

\footnotetext{
${ }^{21}$ Recall that in $2016,44.1 \%$ of four-year university graduates were females (see MEXT, 2016a), so 45\% seems like a reasonable assumption for a cohort starting university now.
} 

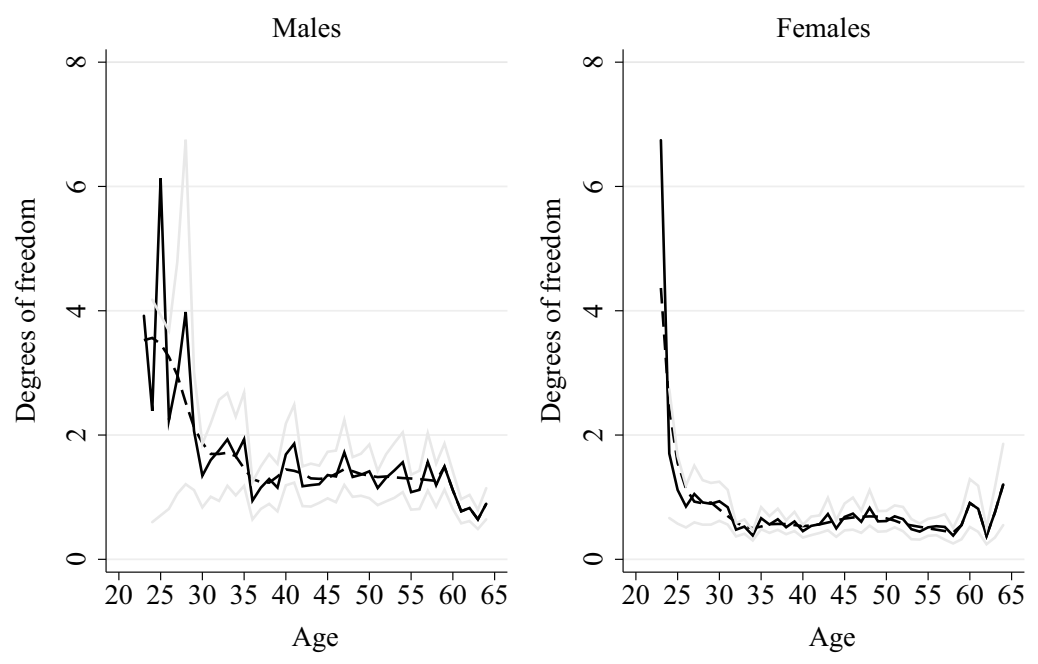

Estimated df

$\mathrm{CI}$

- - - - df used in simulations

Fig. 9. Estimates of degrees of freedom $(\nu)$ from t-copula.

Table 2

Comparison of earnings correlations in JHPS/KHPS panel data and simulated earnings data.

\begin{tabular}{lllll}
\hline Lag & $\begin{array}{l}\text { Males } \\
\text { JHPS/KHPS Panel }\end{array}$ & Simulations & $\begin{array}{l}\text { Females } \\
\text { JHPS/KHPS Panel }\end{array}$ & Simulations \\
\hline 1 & 0.8856 & 0.9067 & 0.8821 & 0.9159 \\
2 & 0.8241 & 0.8248 & 0.8324 & 0.8389 \\
3 & 0.7683 & 0.7487 & 0.7963 & 0.7677 \\
\hline
\end{tabular}

1 Drawing a sample of 9,000 females and 11,000 males aged 23 who are placed in 100 percentiles of the earnings distribution ( 90 women and 110 males in each percentile).

2 Estimating the conditional distribution of the marginal CDF at age $24\left(u_{24}\right)$ given the marginal CDF at age $23\left(u_{23}\right)$ which is given by: $c_{u_{23}}\left(u_{24}\right)=\frac{\partial}{\partial u_{23}} C_{23}\left(u_{23}, u_{24}\right)$

where $\mathrm{C}_{23}$ is the t-copula with parameters $v$ and $\rho$ from our smoothed estimates at age 23 .

3 Generating a random standard uniform variable $r$ with the same dimension as $u_{23}$ (9,000 for females and 11,000 for males).

4 Generating $u_{24}=c_{u_{23}}^{-1}(r)$ to get our uniformly distributed predicted rank at age 24 , which has a stochastic element due to the rank prediction being partly determined by the draw from the random uniform.

5 Repeat steps 2 to 4 for each sequential age. This gives us the predicted percentile of every individual at each age from 23 to 65 .

6 Matching in smoothed percentile earnings estimates by age and gender from the LFS (some of which are shown in Figs. 7 and 8) to obtain our lifetime earnings simulations.

How do our simulations perform? In Table 2, we compare earnings correlations (including zeros) from our panel with earnings simulations from our t-copula model. We do this for up to three lags of earnings in each data set using all available observations. This was not possible in Dearden (2018) as her panel data only involved two earnings observations whereas the Japanese panel data has up to 13 observations per individual.

The results in Table 2 are very reassuring. Despite only modeling first-order rank dependence, the correlations from our simulations match those observed in our panel data very closely. For the first two lags, the simulated correlations are slightly above the observed correlations, and at lag 3 they are slightly below.
Of course, mobility and dependence trends are likely to change for future graduates and, as mentioned earlier, there is growing evidence of increasing mobility in Japan as the graduate labor market changes. The copula models used in this paper only consider first-order rank dependence, and it appears that this might not be totally adequate (as evidenced by the slightly lower correlation for earnings 3 years apart). If we have too much mobility in our simulations, we will underestimate the cost of an ICL loan system (Dearden, 2018). Table 2, however, suggests that this is unlikely to be very large.

\section{The need for reform of JASSO loans}

\subsection{Policy context}

Japan faces a reduced capacity for public financial support for higher education. The burden of student loans on families is increasing, due either to stagnant household disposable incomes or through exposure to repayment hardship and default. Should Japan continue to shift the cost burden of higher education from the public to private sources, as is the general trend internationally? And what role, if any, is there for government policy to manage the trend of shifting the financing burden from parents to the student?

Kobayashi (2017) shows that there has been rising inequality in access to university between 2006 and 2016 based on two nationwide surveys of high school students or their parents: the 2006 CRUMP, High School Student Survey (see Kobayashi \& Liu, 2013) and the 2016 Parent Survey of High School Leavers (see Kobayashi, 2017).

In 2006 , only $35 \%$ of high school leavers in the lowest income class enrolled in university, compared to $61 \%$ in the highest income class. Enrolment in private universities was highly correlated with income, with the enrolment rate for the highest income group (49.0\%) more than double that of the lowest $(23.2 \%)$ in this survey. This was not the case, however, at national and public universities, where enrolments for all income groups were around $10 \% .{ }^{22}$ National and public universities contributed to widening access to higher education to low-income groups by offering relatively inexpensive tuition fees compared to private universities and enrolment. ${ }^{23}$

\footnotetext{
${ }^{22}$ Being $9.1 \%$ for the lowest income group and $11.9 \%$ for the highest income group.

${ }^{23}$ Most national and public universities and colleges are highly selective, but their missions are to offer the opportunity of higher education to all people.
} 
This situation appears to have changed, based on data from the 2016 Parent Survey of High School Leavers. The enrolment rate in private universities continues to be highly correlated with income, as in the 2006 survey. However, the enrolment rate at national and public universities and colleges is now also correlated with income, which was not seen in the 2006 survey. The private university enrolment rate of the lowest income group is about $28.8 \%$, while that of the highest income group is around $53.6 \%$ in the 2016 survey. The enrolment rates at national and public universities were $10.7 \%$ in the lowest income group and $17.4 \%$ in the highest income group. Inequality of access has increased over the decade for public and national universities. The financing burden on both students and households appears to have adversely affected participation in higher education, especially for private four-year universities and colleges (Kobayashi, 2016).

This pattern of enrolment for the highest achieving students from families in the lowest income group has also changed. The enrolment rate of the highest achievers from the lowest income group fell from $65 \%$ in 2006 to $62 \%$ in 2016, while students in families from the highest income group rose from $71 \%$ in 2006 to $76 \%$ in 2016 . Enrolling in higher education for high achieving students from families in the lowest income also appears to have become more difficult.

This widening inequality in national and public universities is consistent with surveys conducted in 2012, 2013, 2016, and 2017 that confirm the trend (Kobayashi \& Wang, 2018). The growth in student loans from the government, administered through JASSO, has not succeeded in reducing the inequality of access to higher education (Kobayashi, 2014).

The inequality of access to university education among family income classes was one of the main reasons for the introduction of a new grant scheme and partial income contingent loan scheme for undergraduates in 2017. Inequality of access would be a much larger social issue in Japan without the cultural norm and expectation of support from parents. But the ability of parents to finance their children's higher education is becoming more constrained as tuition fees outpace household disposable income growth (Fig. 3). Further solutions are needed.

\subsection{Repayment burdens of the current JASSO loan}

To look at the repayment burdens associated with the current JASSO TBRL, we use the detailed distribution of JASSO loans from JASSO (2014) summarized in Table 1 and allocate loans consistent with this distribution to our graduate earnings simulations. We assume that the amount of loan that a person takes out is negatively correlated with their lifetime earnings with a correlation of -0.3 . As we outlined in Section 2, the amount of JASSO loans taken out by students is negatively correlated with parental household income. We would, therefore, expect the JASSO loan amount to also be negatively correlated with graduate earnings assuming there is some degree of intergenerational earnings immobility. ${ }^{24}$ The more negatively correlated the loan is with graduate earnings, the higher the cost of an ICL. This is important when we consider the cost of the current Japanese Type 1 ICL loan in Section 5.

In our simulated sample, the average Type 1 loan for a four-year degree is 2.23 million yen, with a standard deviation of 0.89 million yen. This is taken out by $14.2 \%$ of students (consistent with the latest figures for 2016 shown in Fig. 4). The average Type 2 loan taken out for a four-year degree is 3.86 million yen, with a standard deviation of 2.08 million yen, taken out by $24.0 \%$ of students. Overall, the average JASSO loan for our sample is 3.25 million yen with a standard deviation of 1.90 . The average payment duration of the loan is 17.5 years.

This allows us to calculate the average repayment burden for

\footnotetext{
${ }^{24}$ The opposite is true in the US, where the students taking out the highest loans tend to be the highest earners (Dearden, 2018).
}

individuals in the 20th percentile of the earnings distribution at each age. We have 20,000 individuals in our simulations so there will be 200 individuals who fall into the 20th percentile. We choose the 20th percentile as this is typically the point in the distribution on which international comparisons of repayment burdens (RBs) are made. The repayment burden is simply the average student loan repayment for individuals in that percentile as a proportion of 20th percentile earnings at each age for males and females. We do this for the simulations with dynamics and with no dynamics in Table 3 . It is the latter that is typically done with $\mathrm{RB}$ analysis comparisons. Allowing for dynamics does not affect these calculations in a significant way as those moving in and out of the 20th percentile of the earnings distribution at each age have similar average JASSO loans and hence repayments. In calculating the average $\mathrm{RB}$, we cap the top $\mathrm{RB}$ at $100 \%$ and report this as greater than $100 \%$.

We can see from Table 3, that for males in the 20th percentile of the earnings distribution, RBs can be as high as $31 \%$ at age 23 but fall to below $10 \%$ from age 26 onwards. For women, the RBs for those in the 20th percentile of earnings stays relatively stable from the ages of 23 to 28 at between $13-20 \%$ (which is comparatively low by international standards) but then dramatically rise and are above $100 \%$ from the age of 31. Recall from Figs. 5 and 6 that at young ages, female graduates in the bottom half of the earnings distribution earn more than male graduates (who are more likely to wait for seishain) hence why RBs are higher for males at very young ages.

Focusing just on individuals in the 20th percentile of the earnings distribution is somewhat arbitrary given the variation in JASSO loan repayments and duration. In Table 4 we follow Dearden (2018) and count how many times over the term of the JASSO loan an individual faces an "excessive" RB of greater than $18 \%$. The choice of $18 \%$ is rather arbitrary but has been suggested in work by Salmi (2003). We again do this for our simulations with and without dynamics.

The first striking finding from the Table 4, is that if we don't include dynamics, we underestimate the proportion of individuals facing at least one period of having an excessive RB. We see that just over $40 \%$ of male graduates and almost $75 \%$ of female graduates face RBs of over $18 \%$ at least once during their loan repayment period. If we instead assumed no earning dynamics, these figures are much lower: $25 \%$ for males and $40 \%$ for females. We also see that $11 \%$ of males and $48 \%$ of females face five or more years of high RBs using our preferred dynamic earnings simulations.

The above figures illustrate why there has been an increasing problem of JASSO loan default. More than 325,000 borrowers had overdue repayments on their loans in 2015, up from about 262,000 in 2005. In 2012, JASSO had to sue 6,193 former students for outstanding debts, up from only 58 in 2004 (Kikuchi, 2018). JASSO measures the default rate as the number of loan recipients who have repayments that are at least three months overdue, divided by the total number of borrowers. In 2015 , this was $4.2 \%$ or approximately 165,000 borrowers in total.

In calculating these RBs we have ignored the fact that JASSO loans offered since 2014 allow a deferral of up to 10 years of JASSO loan repayments for low-income borrowers. This deferral, however, is not automatic and has had quite a low take-up, although the numbers seeking deferral have risen in recent years.

\section{Possible directions for reform: universal income contingent loans}

\subsection{Introduction}

In this section we examine the current JASSO ICL for Type 1 loans and then suggest ways of improving the design and extending the coverage of JASSO ICLs. To do this accurately, we must not only estimate graduate earnings but also those of spouses to estimate taxable income, which is gross earnings minus allowable income deductions as discussed in Section 2. In our simulations, we model the basic 
Table 3

Average JASSO loan repayments and repayment burdens at the 20th percentile of the age-earnings distribution.

\begin{tabular}{lllllll}
\hline Age & $\begin{array}{l}\text { No Dynamics } \\
\text { Average annual } \\
\text { loan repayment } \\
(10,000 ¥)\end{array}$ & $\begin{array}{l}\text { Male } \\
\text { RB } \\
(\%)\end{array}$ & Female & $\begin{array}{l}\text { Dynamics } \\
\text { Average annual } \\
\text { loan repayment } \\
(10,000 ¥)\end{array}$ & $\begin{array}{l}\text { Male } \\
\text { RB } \\
(\%)\end{array}$ & $\begin{array}{l}\text { Female } \\
\text { RB (\%) }\end{array}$ \\
\hline 23 & 18.4 & 31.2 & 13.7 & 17.8 & 30.3 & 13.2 \\
24 & 18.4 & 15.5 & 13.7 & 17.8 & 15.0 & 13.3 \\
25 & 18.4 & 11.1 & 14.4 & 16.0 & 9.7 & 12.5 \\
26 & 18.4 & 9.1 & 15.6 & 18.5 & 9.2 & 15.7 \\
27 & 18.4 & 8.0 & 17.5 & 19.0 & 8.3 & 18.1 \\
28 & 18.4 & 7.3 & 20.2 & 17.3 & 6.9 & 19.1 \\
29 & 18.4 & 6.9 & 24.3 & 18.7 & 7.0 & 24.7 \\
30 & 18.4 & 6.6 & 30.4 & 18.1 & 6.5 & 29.9 \\
31 & 18.4 & 6.4 & $>100.0$ & 20.1 & 7.0 & $>100.0$ \\
32 & 18.4 & 6.2 & $>100.0$ & 16.3 & 5.5 & $>100.0$ \\
33 & 18.4 & 6.1 & $>100.0$ & 19.4 & 6.4 & $>100.0$ \\
34 & 18.4 & 5.9 & $>100.0$ & 18.0 & 5.8 & $>100.0$ \\
35 & 18.4 & 5.8 & $>100.0$ & 17.5 & 5.5 & $>100.0$ \\
36 & 19.4 & 5.9 & $>100.0$ & 20.2 & 6.2 & $>100.0$ \\
37 & 20.3 & 6.1 & $>100.0$ & 21.0 & 6.3 & $>100.0$ \\
38 & 20.6 & 6.0 & $>100.0$ & 21.6 & 6.3 & $>100.0$ \\
39 & 20.6 & 5.8 & $>100.0$ & 22.7 & 6.4 & $>100.0$ \\
40 & 20.6 & 5.6 & $>100.0$ & 22.8 & 6.2 & $>100.0$ \\
41 & 24.4 & 6.4 & $>100.0$ & 25.5 & 6.7 & $>100.0$ \\
42 & 24.4 & 6.2 & $>100.0$ & 26.3 & 6.7 & $>100.0$ \\
\hline & & & & & &
\end{tabular}

Table 4

Measures of years of excessive RBs for JASSO loans.

\begin{tabular}{lllll}
\hline $\begin{array}{l}\text { Number of years of } \\
\text { excessive RBs }>18 \%\end{array}$ & Males & & Females & \\
& & & & \\
\hline 0 & No dynamics & Dynamics & No dynamics & Dynamics \\
1 & 73.21 & 58.02 & 58.54 & 25.28 \\
2 & 7.84 & 14.30 & 0.76 & 7.93 \\
3 & 5.67 & 8.31 & 0.85 & 6.09 \\
4 & 2.41 & 4.87 & 0.50 & 6.48 \\
5 & 1.61 & 3.23 & 1.70 & 6.00 \\
6 & 0.68 & 2.25 & 0.85 & 5.26 \\
7 & 0.73 & 1.71 & 2.06 & 5.70 \\
8 & 0.52 & 1.38 & 1.18 & 4.49 \\
9 & 0.50 & 1.17 & 1.56 & 4.19 \\
10 & 0.19 & 0.77 & 2.56 & 3.83 \\
11 & 0.33 & 0.47 & 2.41 & 3.62 \\
12 & 0.35 & 0.77 & 1.18 & 3.30 \\
13 & 0.19 & 0.44 & 2.88 & 3.33 \\
14 & 0.17 & 0.47 & 2.38 & 2.76 \\
15 & 0.45 & 0.42 & 1.82 & 2.47 \\
16 & 0.19 & 0.33 & 1.62 & 2.20 \\
17 & 0.38 & 0.42 & 0.50 & 1.72 \\
18 & 0.02 & 0.35 & 1.32 & 1.43 \\
19 & 1.75 & 0.19 & 4.73 & 1.40 \\
20 & 0.00 & 0.05 & 0.26 & 0.74 \\
& 2.83 & 0.09 & 10.34 & 1.78 \\
\hline
\end{tabular}

deduction, employment deduction, and social security deductions for health and pensions, as well as deductions for spouses (which depend on both the main earner's salary and their spouse's earnings).

This means that we need to model marriage dynamics. To do this, we assume that our 9,000 female graduates ( $45 \%$ of all graduates) and 11,000 male graduates (55\% of all graduates) will end up in 15,400 graduate household units by the age of 40 (based on marriage formation data for graduates from the LFS). For these households, we make the following assumptions.

- $51 \%$ of female BA graduates and $42 \%$ of male graduates will end up marrying each other (4,600 couples in our simulated sample).

- $25 \%$ of male and $24 \%$ of female graduates will remain single.

- $32 \%$ of male and $25 \%$ of female graduates will marry non-BA partners.
- At the age of 23 , virtually all graduates are single, which steadily changes until the age of 40 . We assume that households do not change after the graduate is aged 40 (so we ignore divorce, death, etc.).

- We allocate spouses by assuming that future spouse's earnings are correlated at the age of 23 (before marriage) with a correlation of 0.3 (reflecting some assortative mating).

We simulate household earnings of graduates by marriage type and work out spouse's earnings (the difference between household earnings and the graduate's earnings) once they are married. Once this is done, we calculate taxable income for males and females at each age. The JASSO ICL involves graduates paying back $9 \%$ per of what we term taxable income (gross income minus income deductions). However, the scheme also involves a minimum repayment of 2,000 yen per month (24,000 yen per year) even when a person has no taxable income. This means that a significant proportion of graduates face very high RBs with this ICL. Further, graduates can choose whether they opt for the ICL or TBRL before they graduate. Graduates who took out low monthly loans of 6,400 yen or less $(307,200$ yen in total) would always opt for the TBRL, as monthly repayments under the TBRL are less than 2,000 yen per month (and hence they are always better off with a TBRL). We estimate that this covers around $7 \%$ of Type 1 borrowers.

\subsection{Current JASSO ICL loan}

We use our simulations to calculate the distributional implications of the JASSO ICL loan and compare the case where we assume there are no earnings dynamics and where there are earnings dynamics. We exclude borrowers with a debt of less than 307,200 yen as they will always opt for the TBRL. The distributional and financial implications of the current Japanese ICL for Type 1 loans is shown in Fig. 10.

A similar exercise was carried out by Kawagoe, Ito and Takara (2018), although they did not use panel data but instead relied on predicting transitions based on background characteristics using estimates from the JGSS cross-sectional data (discussed earlier). They also assumed that all individuals took out a loan of 2.36 million yen, very close to our average Type 1 loan of 2.33 million yen. This means they could not exclude borrowers who would be better off under the TBRL. They discounted loan values back to the age of 22, not 18 as we do in our paper. We discount back to 18 (when the first loan is taken out) as we wanted to calculate the costs of interest subsidies during university as part of the costs of the loan system. Unlike this paper, they did not model marriage formation, but instead conducted simulations assuming that everybody remained single or, alternatively, that everybody married at age 29. They also ignored spousal deductions in calculating taxable income. Despite these differences, our estimated costs of the Type 1 JASSO ICL are reasonably similar. Taking a weighted average of their estimates with a $0.1 \%$ discount rate, they came up with a subsidy of $25.5 \%$ with no mobility and $4.3 \%$ with mobility.

We calculate that the current Japanese ICL involves a subsidy of around $7 \%$ using our preferred dynamic simulations. If we assume no dynamics, the subsidy is estimated to be $14 \%$. The subsidy for the TBRL version of the JASSO Type 1 loan is $4 \%$ with an assumed government discount rate of $0.33 \%$. This compares favorably with the subsidies involved in most international ICLs. However, it has two major problems.

Firstly, it is based on taxable income, which makes using employer withholding for the ICL impossible. Secondly, it involves a minimum repayment, which means that RBs will be greater than $100 \%$ for all individuals earning below 24,000 yen a year (the ICL minimum repayment) with an outstanding debt. 


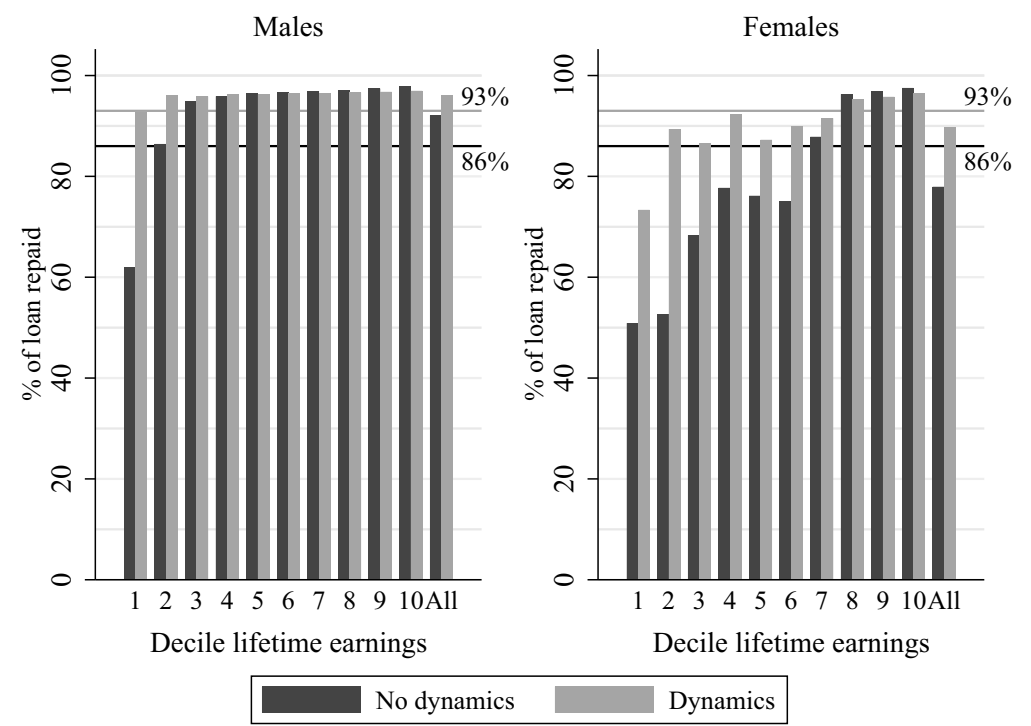

Fig. 10. Distributional implications of current JASSO ICL for Type 1 loans.

\subsection{An alternative design}

The problems outlined in the previous section could be solved by introducing employer withholding and basing the ICL repayments on gross rather than taxable income. Given this is how social security contributions are deducted in Japan, it should be straightforward for an ICL and would ensure that repayments were based on contemporaneous earnings, an essential element of a well-designed ICL (Barr et al., 2019).

Our proposed ICL scheme has the following elements: a marginal repayment rate of $9 \%$ on gross earnings above 3 million yen per year but also a lower marginal repayment rate of $5 \%$ on gross earnings between 1.44 million and 3 million yen (as a substitute for the minimum repayment in the current JASSO ICL-type loan). We assume a zero interest rate, which is the interest rate with the current Type 1 loan. Importantly, we would impose a loan fee or surcharge of $15 \%$ to ensure that the loan is fully self-funding (rather than a minimum charge). This surcharge is equivalent to a discount to those paying upfront tuition fees and has been applied in other countries with ICLs (e.g., Australia). Many countries with ICLs do not have fully self-funding systems and choose to have subsidies. The size of any subsidy would be a Japanese policy choice. $^{25}$

Fig. 11 shows the repayment schedule for both the current JASSO Type 1 loan and our proposed modification. The scatter plot shows the repayments under the current JASSO ICL scheme by gross earnings. The variation in repayments at different levels of gross earnings is due to differences in spousal, pension and health insurance deductions for individuals with the same gross earnings which results in different taxable income levels and hence ICL repayments.

Under our scheme, a person borrowing 2.4 million yen would have a debt of 2.76 million yen after the $15 \%$ fee or surcharge is applied. Their repayment schedule would depend on their gross earnings and would continue until the debt is discharged or they retire or die. Under this scheme, a graduate earning 4 million yen a year would pay $0.05 *(3,000,000-1,440,000)+0.09 *(4,000,000-3,000,000)$ yen per year, which amounts to 168,000 yen per year. From Fig. 11, we see that this is very similar to what the same person would pay under the current JASSO ICL. However, for earnings above 4 million yen a year, borrowers would pay progressively more than under the current ICL, and for earnings below 4 million yen a year, progressively less. All borrowers earning below 1.44 million yen per year would pay nothing under the proposed ICL scheme rather than the minimum 24,000 yen per year under the current scheme. We follow Barr et al. (2019) and would not allow people to choose between at TBRL and ICL-only an ICL would be available.

What are the cost and distributional implications of this alternative scheme? We see from Fig. 12 that the proposed ICL essentially covers its costs in full. This is because higher-earning graduates pay around $110 \%$ of the loan value in net present value terms and cross-subsidize (insure) the shortfall in repayments from low-earning graduates. The scheme is generally progressive, with higher-earning graduates paying the largest subsidy. For females, we see that with our dynamic simulations, women in the third and fourth deciles pay slightly more than those in the 5th and 6th deciles. This is because of our assumption that debt is negatively correlated with lifetime aggregate earnings, so on average women in these deciles have larger loans. Males on average pay $109 \%$ of the loan value and females pay on average just over $84 \%$ of the loan (all in net present value terms using a discount rate of $0.33 \%$ ). If we assume no earnings mobility, the estimated cost of the loan is $19 \%$.

\subsection{A universal ICL for Japan}

Finally, we model a universal ICL loan. To do this, we assume that the average loan taken out by students is 3.64 million yen over four years and that those currently not eligible for JASSO loans can take out the full range of JASSO loans. Hence the simulations here involve higher average loans than in the earlier simulations, which focused on Type 1 loans only (an average loan of 3.64 million yen instead of 2.33 million). Again, we assume the size of the loan is negatively correlated with lifetime earnings. We impose a $0.33 \%$ interest rate for those taking out Type 2 loans which applies only after graduation. The results of doing this are shown in Fig. 13.

We see that even with significantly higher average loans, the proposed ICL is essentially self-funding. We calculate that $96 \%$ of the costs are recovered. ${ }^{26}$ This is very similar to the subsidy with the current JASSO TBRL (which has a small interest subsidy during university for all students, and for the term of the loan for Type 1 loans). Clearly, this is just one possible type of universal ICL - others with similar subsidies could be designed with different distributional implications (see Barr et al., 2019).

\footnotetext{
${ }^{25}$ See Britton, van der Erve, and Higgins (2019) for a discussion on subsidies and international comparisons.
}

${ }^{26}$ If we assume no dynamics, the estimated subsidy is $21 \%$. 


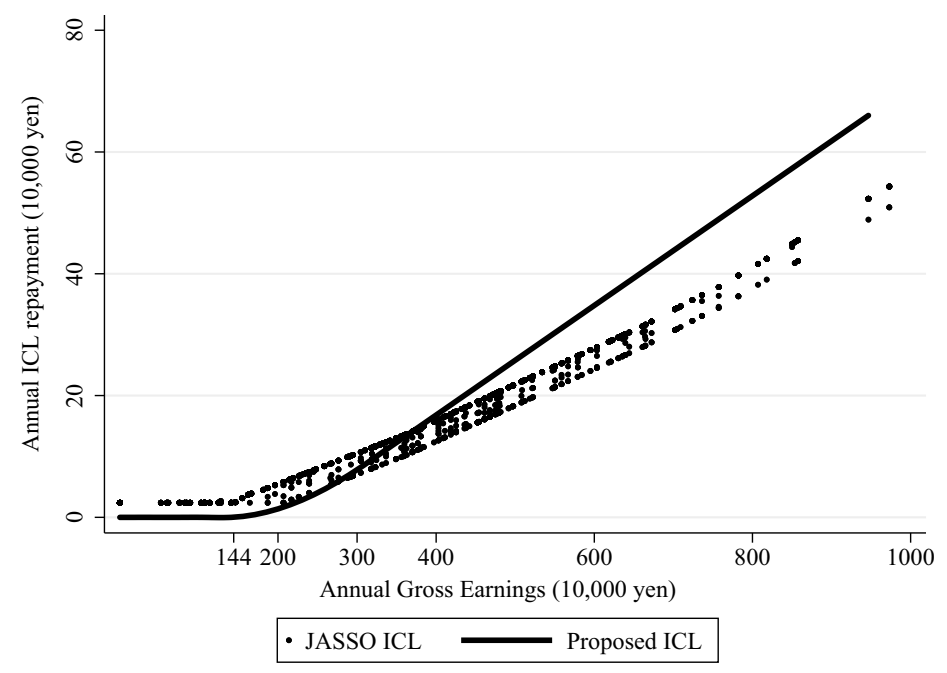

Fig. 11. Repayment schedule for JASSO ICL and Alternative ICL: Type 1 loans only.

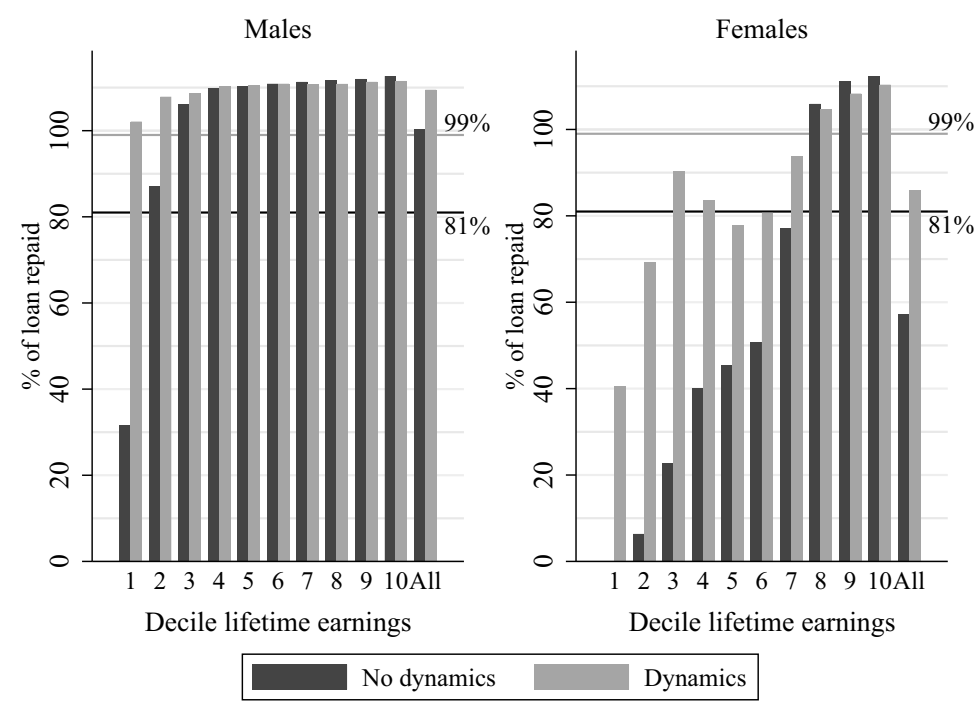

Fig. 12. Distributional implications of alternative ICL: Type 1 loans only.
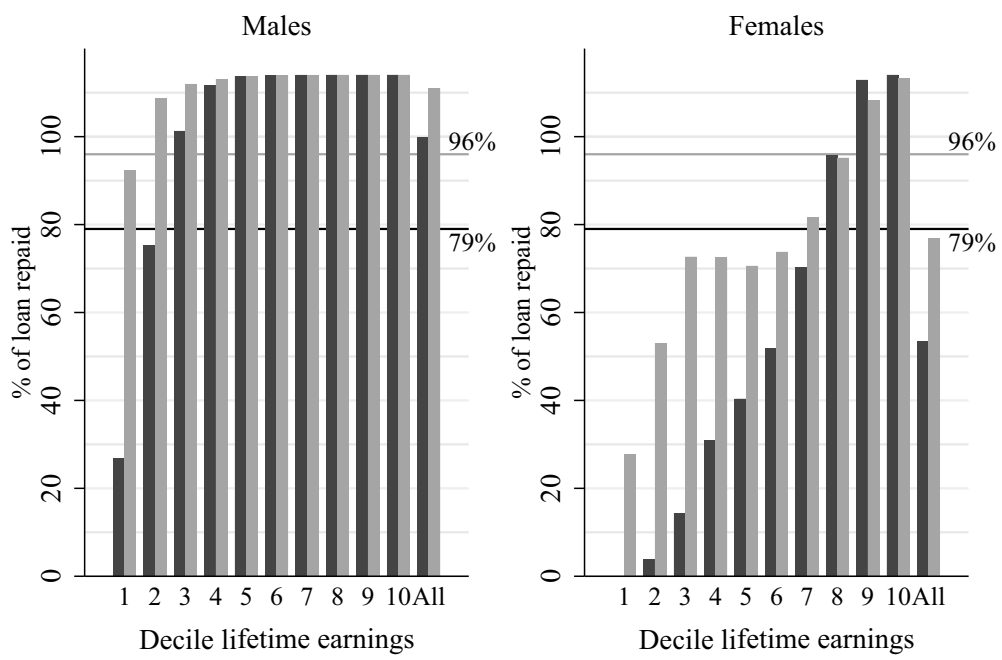

No dynamics

Dynamics

Fig. 13. Modeling a universal ICL. 


\section{Conclusions}

This paper highlights many of the problems with the current JASSO student loan system. We have used LFS data in combination with JHPS/ KHPS panel data to help understand the reasons behind the current problems with JASSO student loans. We have highlighted the importance of not only understanding and considering the distribution of earnings of graduates at each age but also modeling graduate earnings dynamics.

One key issue identified is the unique nature of the Japanese labor market compared to other countries operating ICLs. In particular, the low earnings of female university graduates, once they get married and/or have a child, raises interesting design issues. These low earnings appear to be driven in part by firm, tax and social security policies that give generous tax breaks if wives earn no or low income. These policies are currently under scrutiny and there is some evidence of changing behavior for younger cohorts of women after marriage and having children. However, it is likely to remain a feature of the Japanese graduate labor market for some time.

We argue that most of the problems with the current JASSO loan system could be solved in a fair and efficient way by introducing a universal ICL. The unusual features of the Japanese graduate labor market mean that the parameters of the loan need to be very different from those operating in the United Kingdom and Australia. In particular, to minimize government costs there must be significantly lower repayment thresholds coupled with incremental rises in marginal repayment rates rise as earnings rise. A loan surcharge is probably also needed to reduce taxpayer subsidies and to ensure only those who need loans take them out. ${ }^{27}$ This is to ensure that females early in their career make a significant repayment contribution before they get married and that those with relatively low earnings when married make some further modest repayments. The changing nature of the female labor market, which is evident in more recent cohorts, will also help.

Importantly, the availability of universal loans needs to be restricted to high-quality university and college provision for suitable students in a transparent way. This is always much more difficult in a country where most students go to private universities. This is part of a broader problem with the current Japanese loan system and requires careful thought.

JASSO student loans are available to both two-year college as well as four-year university students and future work needs to ensure that any ICL design would also work for two-year college graduates taking out loans. Given the relatively low repayment thresholds we are proposing, it seems highly likely that this would not pose a problem given the lower debts associated with two-year college. While they have not been considered in our paper, it would be relatively simple to include this in future work.

Finally, we have shown that incorporating realistic dynamics is crucial to developing a self-sustaining universal student loan system that is equitable, affordable and ensures that all deserving students can take full advantage of post-high school education in Japan without any financial barrier. Given recent evidence of increasing inequality in access by household income, this seems very important.

\section{Acknowledgments}

The authors are grateful for feedback received from 4 anonymous referees, Bruce Chapman, and our discussants Nobuo Akai, Hideaki Tanaka, Hideo Akabayashi, Motohisa Kaneko and Naohiro Yashiro and other participants at the "Financing Higher Education in Japan"

\footnotetext{
${ }^{27}$ Without a surcharge, the loan would involve a subsidy to all borrowers because of the interest rate subsidy that applies during university which would mean that even those not needing loans might take them out because of the favourable terms of the loans.
}

conference held on 4 October 2017 at International House, Tokyo. The authors are also grateful to the Research School of Economics at the Australian National University and Kazumasa Iwata and Japan Center for Economic Research for their support. The authors are grateful to Sam Hardwick for excellent research assistance and project support. Lorraine Dearden would like to gratefully acknowledge financial assistance received from the ESRC-funded Centre for the Microeconomic Analysis of Public Policy at IFS (grant RES-544-28-5001) and the HEFCE and ESRC funded Centre for Global Higher Education at UCL-IOE (Grant no. ES/M010082/1). Nobuko Nagase would like to gratefully acknowledge financial assistance received from the Japan Society for the Promotion of Science fund (KibanC15K03503), and also by the Joint Usage and Research Center Programs of the Institute of Economic Research, Hitotsubashi University. Permission to use the microdata of Japanese Labor Force Survey was obtained through the Joint Usage and Research Center Programs on the basis of the Statistics Act (Act No. 53 of 2007), Article 32. The Japan Household Panel Survey (JHPS/KHPS), was kindly provided by the Keio University Panel Data Research Center.

\section{Supplementary materials}

Supplementary material associated with this article can be found, in the online version, at doi:10.1016/j.econedurev.2018.10.012.

\section{References}

Barr, N., Chapman, B., Dearden, L., \& Dynarski, S. (2019). The US college loans system: Lessons from Australia and England. Economics of Education Review, 71, 32-48. https://doi.org/10.1016/j.econedurev.2018.07.007.

Britton, J., van der Erve, L., \& Higgins, T. (2019). Income contingent student loan design: Lessons from around the world. Economics of Education Review, 71, 65-82. https:// doi.org/10.1016/j.econdedurev.2018.06.001.

Dearden, L. (2018). Evaluating and Designing Student Loan Systems: An overview of empirical approaches. Economics of Education Review, 71, 49-64. https://doi.org/10. 1016/j.econedurev.2018.11.003.

Dearden, L., \& Nagase, N. (2017). 'Getting student loans right in Japan: Problems and possible solutions'. Tokyo: Institute of Economics Research, Hitosubashi University Discussion Paper Series 668.

Dearden, L., Fitzsimons, E., Goodman, A., \& Kaplan, G. (2008). Higher education funding policy. Economic Journal, 118(526), F100-F125.

Dearden, L., \& Nascimento, P. (2018). Modelling alternative student loan schemes for Brazil. Economics of Education Review, 71, 83-94. http://doi.org/10.1016/j. econedurev.2018.11.005.

Higgins, T., \& Sinning, M. (2013). Modeling income dynamics for public policy design: An application to income contingent student loans. Economics of Education Review, 37, 273-285.

JASSO. (2017). Annual Report 2017-2018 https://www.jasso.go.jp/en/about/ organization/ icsFiles/afieldfile/2017/10/16/jassooutline2017-2018.pdf.

Kawagoe, M., Ito, Y., \& Takara, M. (2018). What do microsimulations tell us about fiscal costs of the newly launched income contingent loans in Japan? ESRI Discussion Paper Series No.343, January.

Kobayashi, M. (Ed.). (2016). Perspectives of student financial assistance policies: lessons for Japanese higher education, center for research and development of higher education. The University of Tokyo/Japan Student Services Organization.

Kobayashi, M., \& Liu, W. (2013). Access and cost-sharing in Japanese higher Education: Tuition and student financial aid Policy, updated in 2012, center for research and development of higher education. Tokyo: The University of Tokyo.

Kotokyoikukikan shingakujino kakeifutannni kansuru chosa kenkyu. In M. Kobayashi (Ed.). (The University of Tokyo) (A Report on the Survey on the Financial Burden of Family for Higher Education), Tokyo Daigaku.

Kateino Keizaijokyo/ shakaijokyoni kansuru jittaihaaku/bunseki oyobi gakuseitouheno keizaitekishienno arikatani kansuru chosa kenkyuu hokokusho. In M. Kobayashi (Ed.). (The University of Tokyo) (A Report on the Analysis of the Economic and Social Conditions of Family and a Financial Support for Student) Tokyo Daigaku.

Kobayashi, M., \& Wang, J. (2018). Shogakukin Jukyu niyoru Seikatu Jokyo no Soui: JHPS Daini Sedai Tsuiseki Chousa Deta ni motozuku Jissho Bunseki. An empirical study of the differences of life style by the receipts of student financial aid: Based on the analysis of JHPS second generation panel data Paper presented at the annual conference of the Japan society for educational sociology, September 4, 2018.

MEXT. (2016a). Statistical Abstract, 2016 Edition. http://www.mext.go.jp/en/ publication/statistics/title02/detail02/1379369.htm.

MEXT. (2016b). School Basic Survey (Gakko Kihon Chosa) FY2016. http://www.mext.go. jp/en/news/topics/detail/1397166.htm.

MEXT. (2017). Major Issues in the Budget of Higher Education Bureau 2017. http://www. mext.go.jp/component/b_menu/other/_icsFiles/afieldfile/2017/01/12/1381133_ 01_1.pdf (in Japanese). 
Miyamoto, H. (2016). Reforming Japan's dual labour market. East Asia Forum. 23 December. http://www.eastasiaforum.org/2016/12/23/reforming-japans-duallabour-market/.

Nagase, N. (2011). 2000 nen igo no Danjo no Shitugyo Kozo no Bunseki-Rodoryokuchosa no paneru kozo wo mochiite Kozo Henka wo Bunseki suru (Structural Change in Unemployment by Gender in 2000's using the Panel Structure of Labor Force Survey)'. Tokei to Nihon Keizai (Statistics and the Japanese Economy), 1(1), 91-111 (in Japanese).

Nagase, N. (2017). 2002-2015 nen no josei shugyorituno henka: Abenomikusu no koka ha attaka? (Change in labor supply of females during 2002-2015: Has abenomics worked?). Tokei (Statistics), 68(2), 54-58 (in Japanese).

Nagase, N. (2018a). Has Abe's WOMANOMICS worked? Asian Economic Policy Review, 13(1), 68-101.

Nagase, N. (2018b). Measures to close the wage gap of standard and non-standard workers: The effect of bunching of married hourly female workers at non-tax levied income thresholds (Hiseiki-koyo to Seiki koyo no Kakusa: Josei Wakamono no Jinteki Shihon Kakujuu notameno Shisaku ni tsuite. The Japanese Journal of Labor Studies (Nihon Rodo Kenkyu Zasshi) Special Issue, 691, 19-38 (in Japanese).

Naoi, M., \& Yamamoto, K. (2010). Sampling and representation of JHPS. Joint Research Center for Panel Studies Joint Discussion Paper Series DP2009-004.https://www.pdrc. keio.ac.jp/uploads/DP2009-004.pdf.

OECD. (2015). OECD education at a glance 2015, OECD, Paris. https://www.oecdilibrary.org/education/education-at-a-glance-2015_eag-2015-en.

Salmi, J. (2003). Student loans in an international perspective: The World Bank experience. Washington, D.C.: The World Bank Working Paper no. 27295.

Sklar, A. (1959). Fonctions de Répartition à n Dimensions et Leurs Marges. Institut Statistique de l'Université de Paris, 8, 229-231.

Yashiro, N. (2011). Myths about Japanese employment practices: An increasing insider-outsider conflict of interests. Contemporary Japan, 23(2), 133-155. 